\title{
Experimental Study of Travellerless Magnetic Ring Frame
}

\author{
Part 5: Distribution of Magnetic Force \\ By Ichiro Ohno, Member, TMSJ \\ Japan Wool Textile Co., Ltd., (Nippon Keori K.K.), Kobe.
}

\section{Introduction}

The previous instalments have shown that the force of inner ring adhering to the holder ring is an important factor which decides the quality of the magnetic ring. This force is produced by an irregurlar distribution of the magnetism of the permanent magnets constituting the holder. Permanent magnets must, therefore, be manufactured with the utmost attention paid to a uniform distribution of their magnetism.

The holder is so made that four or six arc-shaped small magnet pieces are combined annularly, or four poles or six poles are polarized on the ferromagnetic substance made in annular shape.

Since the ferro-magnetic substance produces crystal magnetic anisotropy in either case, it is technically difficult to obtain a homogeneous crystal. Even when the poles are polarized uniformly, the annular magnet is not uniform in the strength of magnetism. The magnetism distribution being one of the major factors decisive of the quality of the ring, we have to know how far we may permit the magnetism distribution to be irregular.

The present article relates to an experiment in which the magnetism distribution of a good ring was measured. The ring gave the experimental spinning machine more than 10,000 r.p.m. The result of the measurement was compared with the magnetic distribution of a bad ring in order to obtain data on the manufacture of magnetic rings.

\section{Methods of Measuring Distribtuion of Mag- netic Force}

Method A: Remove the inner ring and measure the strength of the magnetic fieid along the inner wall of the holder with a gauss meter.
Method B: Wind a coil on the inner ring, pull the coil upward in the intermediate position between two poles and mea. sure the magnetic flux density.

Method C: Wind a coil on the inner ring, as in method $B$, rotate the coil by $60^{\circ}$ from one pole to another (if there are six poles) and measure the mag. netic flux density.

Good and bad holders shown in Table 1 were measured by method A. The results, compared in a developable graph, are shown in Fig. 1.

Holder No. 4 had a good magnetic distribution curve capable of giving more than 10,000 r.p.m.

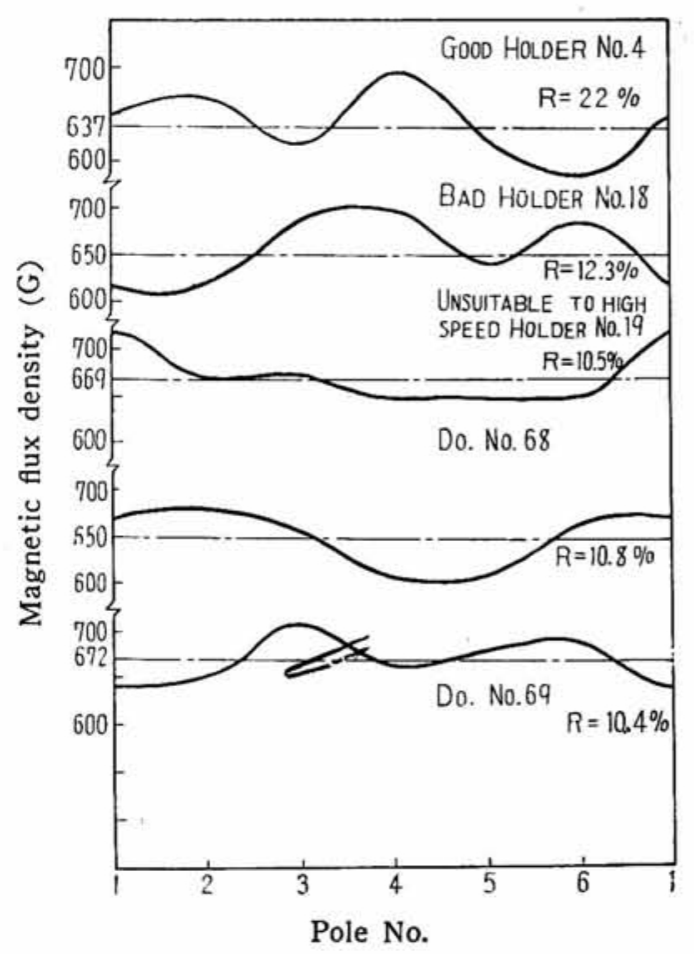

$R$ : Variation range

Fig. 1 Measured with Gauss meter at a point on pole 
Table 1

\begin{tabular}{|c|c|c|c|c|}
\hline Holder No. 4 & Holder No. 18 & Holder No. 19 & Holder No. 68 & Holder No. 69 \\
\hline Good trial & $\begin{array}{l}\text { Bad one picked } \\
\text { from large } \\
\text { quantity of } \\
\text { holders }\end{array}$ & $\begin{array}{c}\text { Same as holder } \\
\text { No. } 18\end{array}$ & $\begin{array}{c}\text { Same as holder } \\
\text { No. } 18\end{array}$ & $\begin{array}{c}\text { Same as holder } \\
\text { No. } 18\end{array}$ \\
\hline $\begin{array}{l}\text { Operable at } \\
\text { more than } \\
10,000 \text { r.p.m. }\end{array}$ & $\begin{array}{l}\text { Operable up to } \\
\text { about } \\
9,000 \text { r.p.m. }\end{array}$ & $\begin{array}{l}\text { Cannot be started } \\
\text { even by changing } \\
\text { the No. of revol- } \\
\text { utions variously }\end{array}$ & $\begin{array}{l}\text { Operable up to } \\
8,000 \text { r.p.m. }\end{array}$ & $\begin{array}{l}\text { Operable up to } \\
8,000 \text { r.p.m. }\end{array}$ \\
\hline $\begin{array}{l}\text { Spinning tension } \\
50.60 \mathrm{~g} \text { at } 2 / 48\end{array}$ & $\begin{array}{l}\text { Same as No. } 4 \\
\text { but meter hand } \\
\text { subject to } \\
\text { large vibrations }\end{array}$ & - & $\begin{array}{l}\text { Spinning } \\
\text { tension } \\
45 \sim 55 \mathrm{~g} \text { at } \\
2 / 48\end{array}$ & $\begin{array}{l}\text { Spinning } \\
\text { tension } 35 \sim 50 \mathrm{~g} \\
\text { at } 2 / 48 \text {, but } \\
\text { meter hand sub- } \\
\text { ject to large } \\
\text { vibrations }\end{array}$ \\
\hline $\begin{array}{l}\text { Reverse } \\
\text { revolutions of } \\
\text { inner ring } 120 \\
\text { r.p.m. at spindle } \\
\text { of speed } 10,000 \\
\text { r.p.m. }\end{array}$ & $\begin{array}{l}\text { Reverse revolu- } \\
\text { tions of inner } \\
\text { ring-110 r.p.m. } \\
\text { at spindle speed } \\
\text { of } 8,000 \text { r.p.m. }\end{array}$ & - & $\begin{array}{l}\text { Reverse revolu- } \\
\text { tions of inner } \\
\text { ring. } 90 \text { r.p.m. } \\
\text { at spindle speed } \\
\text { of } 8,000 \text { r.p.m. }\end{array}$ & $\begin{array}{l}\text { Reverse revolu- } \\
\text { tions of inner } \\
\text { ring- } 91 \text { r.p.m. } \\
\text { at spindle speed } \\
\text { of } 8,000 \text { r.p.m. }\end{array}$ \\
\hline $\begin{array}{l}\text { Gap of inner } \\
\text { ring } 0.7 \mathrm{~mm}\end{array}$ & $\begin{array}{l}\text { Gap of inner } \\
\text { ring } 0.63 \mathrm{~mm}\end{array}$ & $\begin{array}{l}\text { Gap of inner } \\
\text { ring } 0.7 \mathrm{~mm}\end{array}$ & $\begin{array}{l}\text { Gap of inner } \\
\text { ring } 0.6 \mathrm{~mm}\end{array}$ & $\begin{array}{l}\text { Gap of inner } \\
\text { ring } 0.4 \mathrm{~mm}\end{array}$ \\
\hline $\begin{array}{l}\text { Supporting force } \\
\text { of inner ring } \\
\text { (3-mm lifting) }\end{array}$ & " & " & (5) & - \\
\hline $\begin{array}{l}30 \mathrm{~g} \\
\text { Attraction force }\end{array}$ & $27 \mathrm{~g}$ & $26 \mathrm{~g}$ & $27 \mathrm{~g}$ & $29 \mathrm{~g}$ \\
\hline $\begin{array}{c}\text { of inner ring } \\
16 \mathrm{~g}\end{array}$ & $20 \mathrm{~g}$ & $\begin{array}{l}17^{\prime \prime} \mathrm{g} \\
\text { (with two con- } \\
\text { tacting points) }\end{array}$ & $23 \mathrm{~g}$ & $16 \mathrm{~g}$ \\
\hline
\end{tabular}

Holder No. 19 was a bad one and inoperable. The other three holders were examples of rings incapable of giving 10,000 r.p.m.

A comparision of these magnetic distribtuion curves shows that holder No. 4 (good) gives the largest degree of irregularity of the curve; and that holder No. 19 (inoperable) gives a relatively small degree of irregularity of the curve. This fact, which is apparently contrary to the theory, is likewise noticed in the values measured by methods $A, B$ and $C$.

Before proceeding to look into this unexpected phenomenon, we observed the status of the magnetic distribution by another method described in what follows.

Fig. 2 shows a device to measure the attraction force acting upon steel ball $\mathrm{E}$. Holder $\mathrm{C}$ was fixed on plate $A B$ which was capable of inclination to about $O$ as the axis. Groove D inside the holder was fixed on plate $A B$ and was so arranged that steel ball $\mathrm{E}$ could roll freely in the groove. When $\mathrm{AB}$ was inclined, steel ball E, which was attracted, finally detached itself by its own weight. Attraction force $F$ was obtainable as follows from the inclination angle $\theta$ at this time:

$$
F=W \cdot \sin \theta-\alpha \cdot W
$$

where $W$ (in this case 14 g.) is the weight of the steel ball and $\alpha$ is the coefficient of rolling friction.

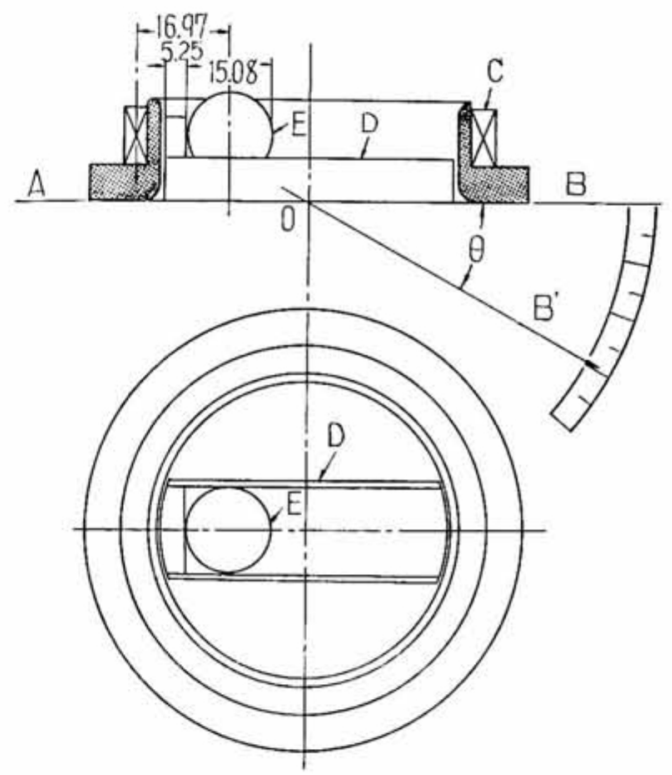

Fig. 2(a) Device to measure attraction force

Dournal of The 7cxtilc Machincry Socicty of Dapan 


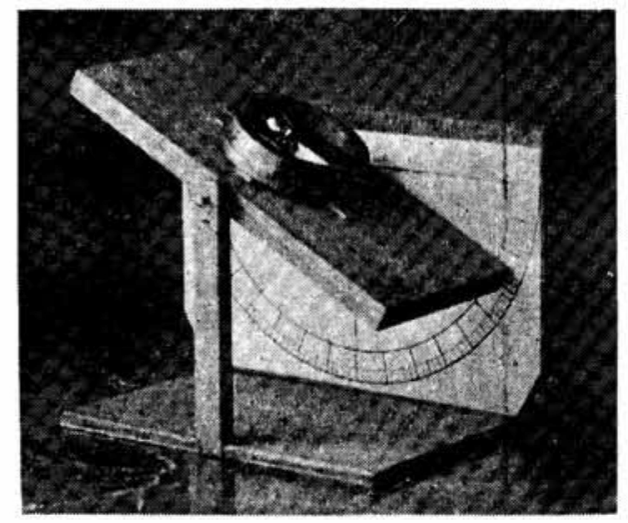

Fig. 2(b) Device to measure attraction force

Fig. 3 compares the magnetic distributions of the various holders measured by this other method. The measuring points were (a) the pole portion where magnetism was the strongest and (b) the middle of each magnetic piece where the magnetism was the weakest. The distribution curve at this time differed slightly in form from the distribution curve obtained by an electro-magnetic measuring method. Still, as before, the irregularity of distribution was the largest with holder No. 4 and smaller with holder No. 19.

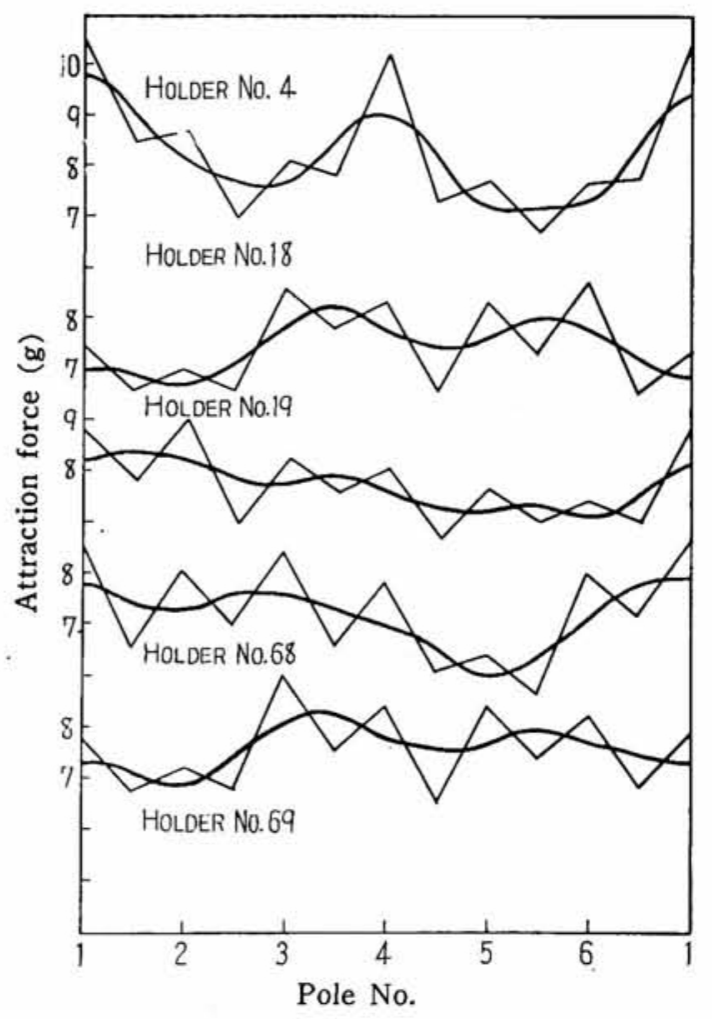

Fig. 3

\section{Reproducibility Magnetic Field}

The purpose of investigating the magnetic distribution is to see whether good rings are obtainable by polarizing a magnetic ring in the same way as a good ring is polarized at time of manufacturer. For this purpose, we disassembled a bad magnetic holder, measured the magnetic force of its individual small magnet pieces by a method which will be described later, and made a new holder by reassembling the pieces artificially in such a way that it gave the same distribution of magnetism as holder No. 4 (good).

Fig. 4 gives a comparison of the magnetic distributions of the new holder and holder No. 4; the distributions are almost the same. With this new holder fitted to the experimental spinning machine and operated under the usual conditions, safe operations up to 9,000 r.p.m., were obtainable, with slight more than usual ends-down at 10,000 r.p.m. However, the new holder differed from holder No. 4 in one point: its inner ring did not revolve reversely. This experiment has thus made it clear that the magnetic distribution of a good holder is artificially reproducible on a bad holder by disassembing it and reasssembing its magnet pieces with this end in view.

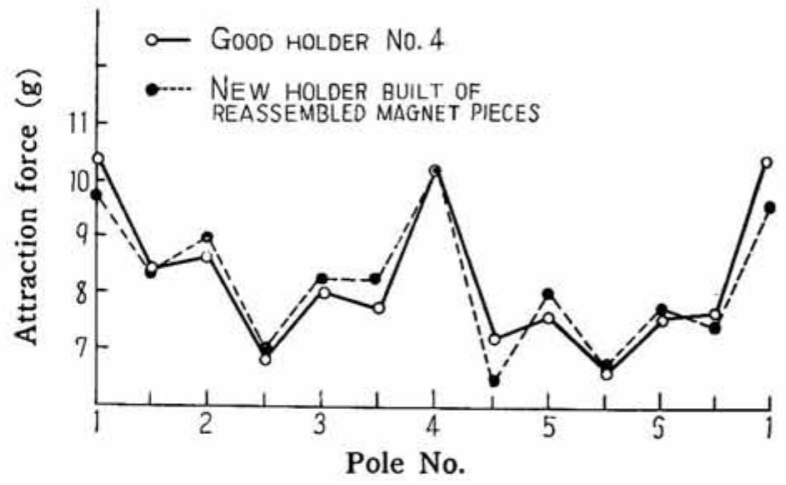

Fig. 4

Now to explain the apparatus used to measure the strength of the disassemble small magnet pieces. $\mathrm{A}$ in Fig. 5 is an inner ring attached to the lower end of pendulum $\mathrm{C}$, which moves freely with $\mathrm{F}$ as the axis. In the upper part of $\mathrm{C}$ there is hand $\mathrm{D}$ which points to point 0 on the dial plate fixed to the other element. Bring small magnet piece $B$ closer to A while keeping it horizontal, as shown in the drawing, and $\mathrm{A}$ is attracted and moves. The value of the distance $l$, through which the hand moves in this case, is proportional to the square of the force of magnet piece. The magnetic force can, 


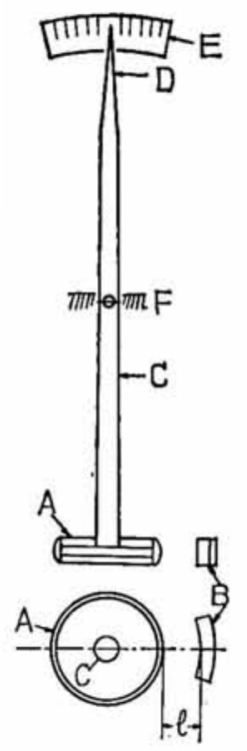

Fig. 5(a) Apparatus to measure the strength of magnet pieces

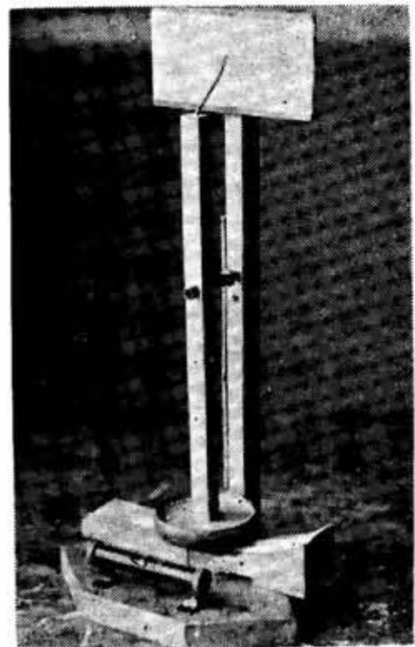

Fig. 5(b) Apparatus to measure the strength of magnet pieces

therefore, be estimated by measuring the distance $l$ explained above.

Table 2 shows a comparision of the magnetic force of each small magnet piece disassembled from the bad holders and measured by the foregoing method. The table shows that there is a considerable difference in magnetic force even among pieces polarized equally after the first assembling. Magnetic pieces polarized after assembling tend to decrease in their magnetic force when disassembled. This tendency varies according to the condition of the crystalization of the individual magnet pieces, a fact which presumably explains the difference in mag. netic force just cited.
Table 2

\begin{tabular}{rccc}
\hline Magnet piece & No. 2 & $\begin{array}{l}\text { Bad holders } \\
\text { No. } 114\end{array}$ & No. 117 \\
\hline & $l^{2}$ & $l^{2}$ & $l^{2}$ \\
No. 1 & $650 \mathrm{~mm}$ & $625 \mathrm{~mm}$ & $729 \mathrm{~mm}$ \\
2 & 576 & 676 & 484 \\
3 & 529 & 576 & 676 \\
4 & 625 & 729 & 600 \\
5 & 576 & 676 & 729 \\
6 & 625 & 729 & 576 \\
\hline
\end{tabular}

\section{Theoretical Consideration of Intensity of the Magnetic Field}

We tried to show in a developing graph the strength of the magnetic force in a horizontal direction acting upon the inner ring and to obtain from its curve some features with which the quality of the ring could be identified, but such features were unobtainable from the first developing graph. The reason, presumably, is that we did not consider the fact that the nuagnetic force acting on the inner ring is the algebrais sum of the magnetic force of the poles confronting one another.

Fig. 6 is a model of the developing graph of the distribution of magnetic force, with the curve of $a_{1} \sin x$ having one cycle shown in I, and the curve of $b_{1} \sin 2 x$ having $2 \pi / 2$ cycle shown in II. The figure is plotted in $a_{1}<b_{1}$; irregularity in II is large. With respect to these two models, the difference in the strength of magnetic force of the poles confronting one another at any point of $x$, say, in the second pole, is :

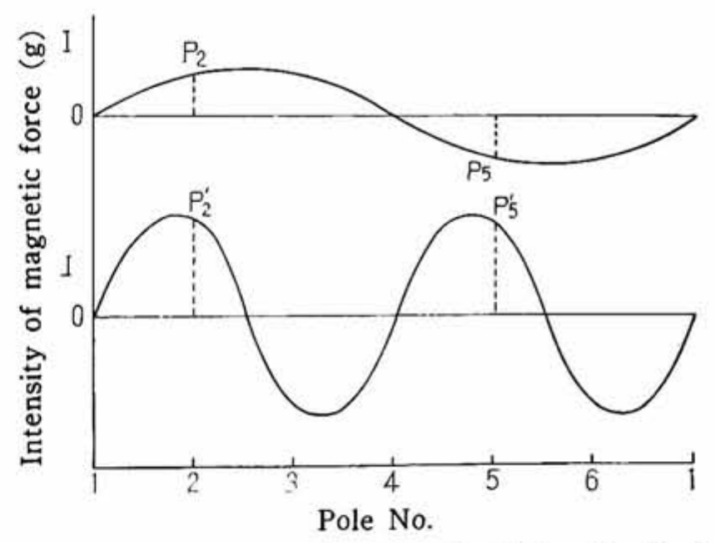

Fig. 6 Model of developing graph of the distribution of magnetic force

gocrosal of The Textile Machinery Society of Dapan 


$$
\begin{array}{cl} 
& \text { For I } P_{2}-\left(-P_{\mathrm{5}}\right)>0 \\
\text { For II } P_{2}^{\prime}-P_{\mathrm{5}}{ }^{\prime}=0 \\
\text { Generally, for I, } a_{1} \sin x-a_{1} \sin (x+\pi)= \\
2 a_{1} \sin x=0 ; \\
\text { for II, } b_{1} \sin 2 x-b_{1} \sin 2(x+\pi)=0
\end{array}
$$

where $0<x<\pi$.

This means that, in any part of the inner ring, the strength of magnetic force compensates in the case of II; but that, in the case of I, the difference in strength of magnetic force is large among all the parts except poles No. 1 and 4 . It seems that the strength of the force by which the inner ring is drawn aside depends on whether the actual distribution curve is close to the curve of I or II.

We may say, in passing, that the degree of irregularity in the developing graph of distribution alone has no direct bearing on the quality of the magnatic ring. However, when the irregularity even in the curve of I decreases (when it is a uniform distribution of magnetic force), $P_{2}-\left(-P_{5}\right) \rightarrow 0$, which is desirable. On the other hand, if $\left(P_{2}^{\prime}-P_{5}{ }^{\prime}\right)$ even in the curve of II departs from 0 and becomes a positive or negative value, it makes a bad distribution.

It is difficult, in practice, to manufacture a magnet ring which can give the curve of II. We are prone to aim at a uniform distribution as the next best thing or as a practicable thing. In that case, irregularity must be reduced to a minimum.

To prove the foregoing theory, we assemble small magnet pieces of equal magnetic force and built a holder having the most uniform magnetic distribution obtainable. We fitted it to the experimental spinning machine and checked its operation condition. Fig. 7 is a developing graph of the magnetic force of this holder. The irregularity of the curve is relatively small and the variations extremely small. A comparison of the magnetic force of the confronting poles of the holder is given in Fig. 8.

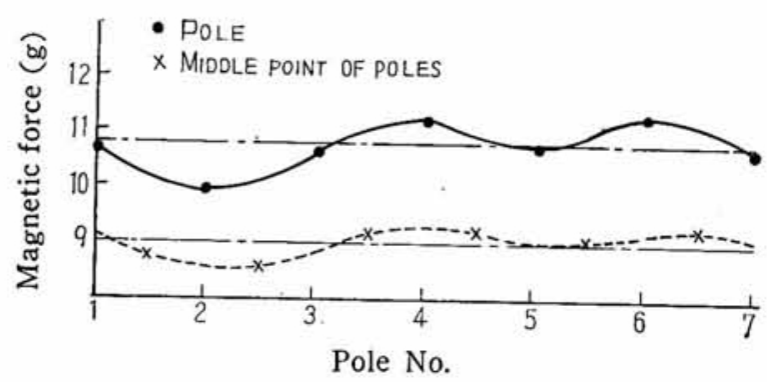

Fig. 7 Devel ping graph of magnetic force where irregularity is relatively small

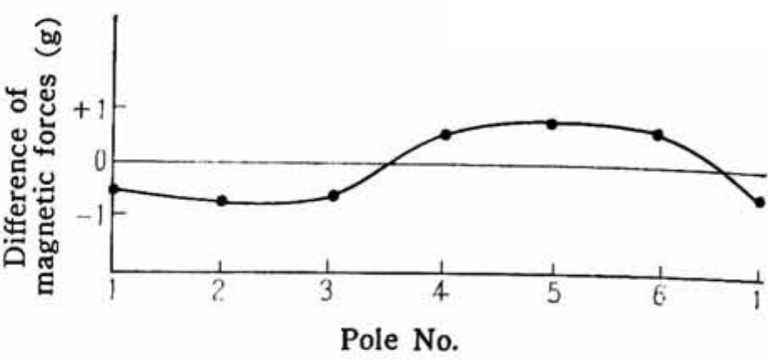

Fig. 8 Difference in magnetic force where irregularity is relatively small

A combination of a strong magnet piece, (A), and a weak one, (C), as in Fig. 9, gives a holder having large variations in distribution (Fig. 10). The measured difference in the magnetic force of its confronting poles is as shown in Fig. 11; it is similar to the previous example.

The two kinds of holders above mentioned were fitted, one after the other, to the experimental spinning machine and their operating conditions checked. Both of them worked well within the limit of about 7,000 r.p.m., but ends-down were frequent at about 9,000 r.p.m. The reverse revolutions of the inner rings of both holders were -83 r.p.m. This fact proves that the two kinds of holder were the same in operating conditions.

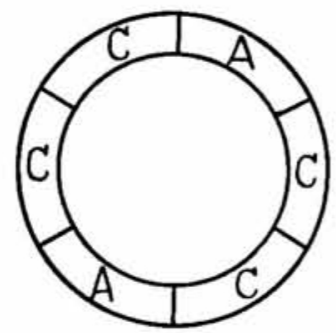

A: Stronger magnetic force

C: Weaker magnetic force

Fig. 9 Arrangement of magnet pieces

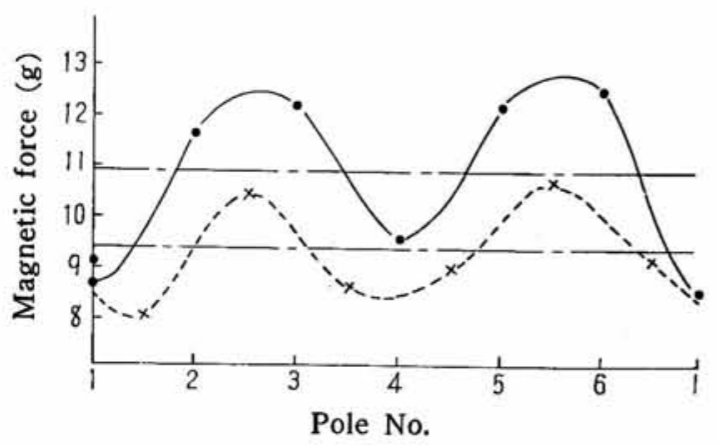

Fig. 10 Developing graph of magnetic force where irregularity is relatively large 


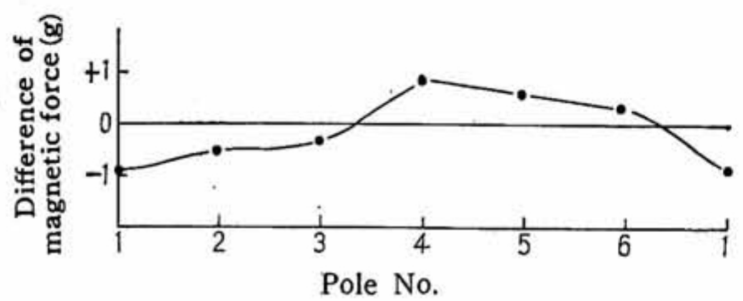

Fig. 11 Difference in magnetic force where irregularity is relatively large

In other words, even if the two kinds of holders differ greatly in distbution curve, they are equal in working conditions if the distribution curves of the difference between the confronting poles are similar.

\section{Actual Distribution of Magnetic Force Studied}

Since the difference in the magnetic force of the confronting poles bears on the quality of the magnet ring, we naturally want to know what shape the distribution curve takes if the difference in magnetic force between them is slight. The model of the distribution curve shown in Fig. 6-II is an ideal one to meet the requirements. There are doubtless many other ideal distribution curves. A holder having an actual distribution curve of magnetic force close to an ideal curve is a good holder.

There are numerous holders made, we picked out one which had been proved to work well and we measured the strength of its magnetic force. We found that it had no set tendency of closeness to an ideal distribution curve and even no commendable feature to speak of. The solid line of Fig. 12 shows the magnetic distribution curve of good holders. The variations in magnetic force to the extent shown will have to be accepted as an error which can occur in the manufacturing process. The irregularity of magnetic force aforementioned seems to be an unavoidable cause for attracting the inner ring to the inner wall of the holder.

As we have already said, we have found it possible by experiment to make a well-working holder by assuming an ideal distribution curve and assembling magnet pieces as closely to the ideal curve as possible. However, the ideal curve was unobtainable from the magnetic distribution curve of such a holder in a reverse experiment.

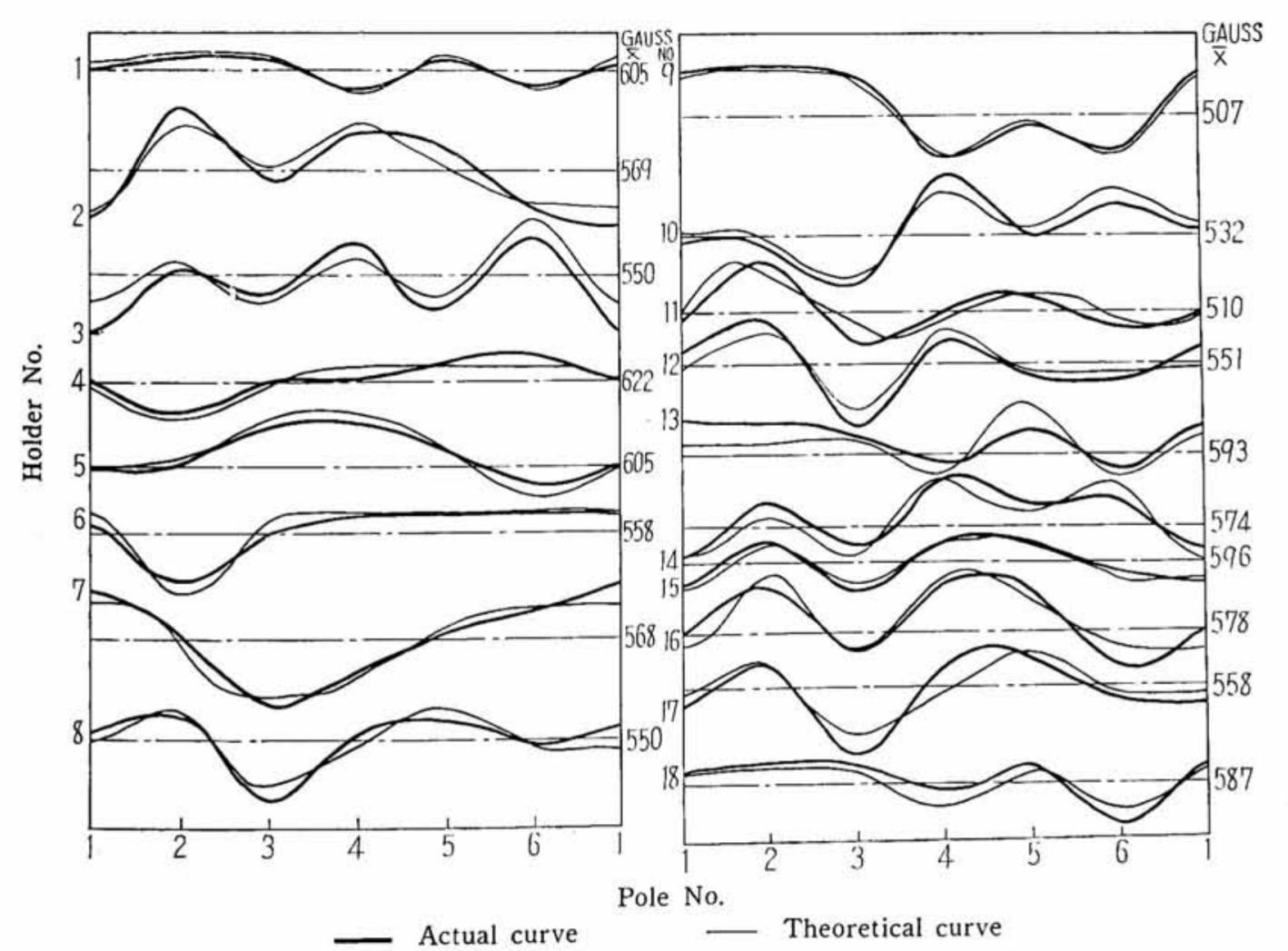

Fig. 12 Developing graph of magnetic force of various holders which are fitted to spinning frame 
However, since the magnetic force of six magnet pieces is distributed in some way or other, it is a matter of course that all kinds of distribution curves of magnetic force can be obtained by combining six magnet pieces differing in magnetism. Assume three kinds of magnet pieces; strong (A), medium (B) and weak (C). There are 729 ways of combining them, but the fact that a ring is a circular permutation reduces the number of 129 , which can be broken down thus:

1. Combination of magnet pieces of equal strength

2. Combination of $(A)$ and $(B)$

3. Combination of (A), (B) and (C)

Excluding magnet pieces having a symmetric form of permutation, we have 91 combinations. The dotted line in Fig. 12 shows a comparison of doveloping graphs of the strength of the magnetic force of combinations of six magnet pieces and the actual magnetic distribution curve of the holder previously obtained. Both are nearly the same.

The amplitude of the theoretical curve in Fig. 12 represents the strength of magnetic force. This varies according to how we assume the relative strength of the magnetic force. A theoretical and an actual curve need not necessarily agree. However, whether the position and periodicity of the peak and dale of the wave in a theoretical curve agree with those in an actual curve is an important point.

We investigated this point by experimenting with a number of holders and found that the actual curves of the position and periodicity of the wave corresponded to either one of the theoretical curves. This fact shows that it is possible to reproduce desired holders by combining the assumed three kinds of magnet pieces.

We are studying whether, in the mass-production of magnet rings, they are to be made by combining individual magnet pieces or whether, holders, each made in an annular piece, are to be polarized. It seems, likely that, in the latter case, a random distribution curve will show, because the strength of magnetic force polarized is not uniform.

The distribution curve of magnetic force actually measured and shown in Fig. 12 hardly resembles the ideal curve shown in formula (2). We investigated whether there was in either curve any kind of curve in which the magnetic force difference of the confronting poles could become zero. We first investigated what periodical curve represented the actual magnetic distribution curve. We found that it was what might be thought of as a complicated periodical curve comprising the coupling of the wave which is represented roughly by the trigonometric function $a_{k} \sin \left(k_{x}+\phi_{k}\right)$. Its resultant wave is represented by the following formula called Fourier series:

$$
\begin{aligned}
& y=a_{0}+a_{1} \cos x+\cdots \cdots+a_{k} \cos k x+\cdots \cdots \\
& +b_{1} \sin x+\quad+b_{k} \sin k x+\cdots \cdots(3)
\end{aligned}
$$

The actual distribution curve being known, the constants $a$ and $b$ are obtainable, but these constants vary individually accroding to the distribution curve. For instance, the solid line in Fig. 13 is the distribution curve of holder No. 4 (good), which, shown in Fourier series, is :

$$
\begin{aligned}
& y \doteqdot-0.667+2.16 \cos x+10.68 \cos 2 x \\
& -0.667 \cos 3 x+3.76 \sin x+1.54 \sin x
\end{aligned}
$$

where the series is adopted up to the third harmonics, and $0<x<\pi$, and $y$ is a number representing the strength of magnetic force.

The difference in the strength of the confronting poles being the difference between the value of $y$ at time of $x$ and the value of $y^{\prime}$ at the time $(x+\pi)$, the following formula is established:

$$
y-y^{\prime}=2\left(a_{1} \cos x+a_{3} \cos 3 x+b_{1} \sin x\right)
$$

The purpose is to obtain the periodical curve which reduces the equation to zero. When the value of $x$ is assumed and the equation is solved, the constants of $a$ and $b$ become all zero and the original formula connot stand. It may be said that, in the resultant wave of theoretical trigonometric function showing such a distribution curve as mentioned above, there is no such periodical curve that the difference between the confronting poles is zero.

The distribution curve of holder No. 4 (good), which is the best curve, is shown in eq. (4). If the difference in magnetic force between its confronting poles is obtained from eq.(5) and then plotted, it is as shown in the upper dotted line in Fig. 13.

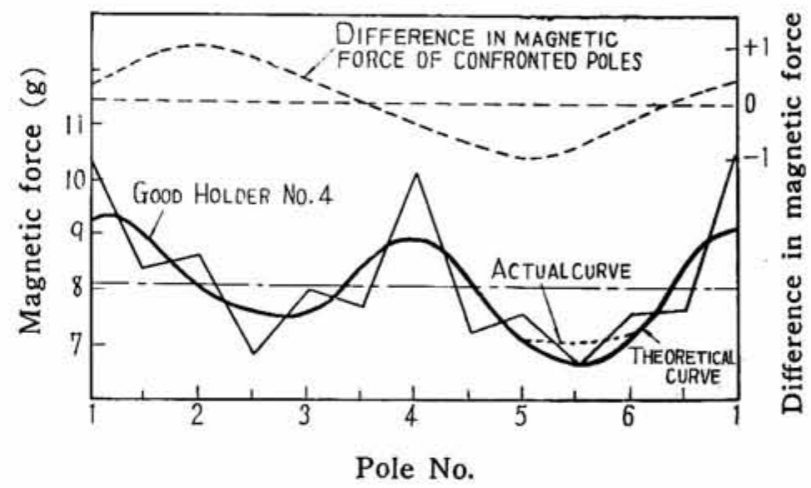

Fig. 13 


\section{Conclusion}

Although we have been unable to obtain a magnetic distribution curve which can be used in judging the quality of a holder, we have made sure that, if magnet pieces assembled into a holder with its mag. netic distribution made in accord with that of a good holder, the newly assembled holder works well.

We have also made sure that, if magnet pieces are so combined that their magnetic force of the confronting poles is theoretically zero, the result is good even if the irregularity magnetic force of the magnetic pieces is large.

However, even if a distribution curve which shows a good result is obtainable, it is difficult to reproduce it in the manufacture of magnet rings, and a uniform distribution has to be sought as the second best thing.

\section{Part 6: Sectional Shape of Inner Ring and Oiling of Holder}

\section{Sectional Shape of Inner Ring and Fuzz of Yarn}

It is common knowledge that cap yarn has more fuzz than ring yarn. The explanation lies mainly in the quality of the wool and partly in the spinning method. The magnetic ring spinning method winds the yarn while it is revolving around the lower edge of the inner ring, just as the cap spinning method does. These methods unavoidably produce some fuzz, as was reported in part 1 . There is no objection to fuzzy yarn after it is made into a textile, but fuzz reduction during processing is desirable.

One way to reduce fuzz is to reduce the frictional resistance between yarn and the inner ring to a minimum. S. Fürst[1] made a research on the frictional resistance between the section of the traveller and yarn and said that the resistance of the passing yarn was the slightest if the traveller had a circular section.

According to this theory, it will do to make the inner ring circular in section, but an inner ring can not be made circular in section because there is a limit to the size of a magnetic ring and also because an inner ring having a circular section lessens the effect of magneto-motive force. Hence the present section shaped like the letter D has to be used.

Nevertheless, it may not be altogether useless to look into the relationship between the section of the inner ring and the fuzz of the yarn. An experiment has, therefore, been made by trially producing inner rings having a rectangular-shaped section and those having a triangular-shaped section.

Fig. 1 shows three inner rings having different sections. In our experiment we used a holder having the section shown in Fig. 2 to keep the yarn from touching the inner wall of the holder.

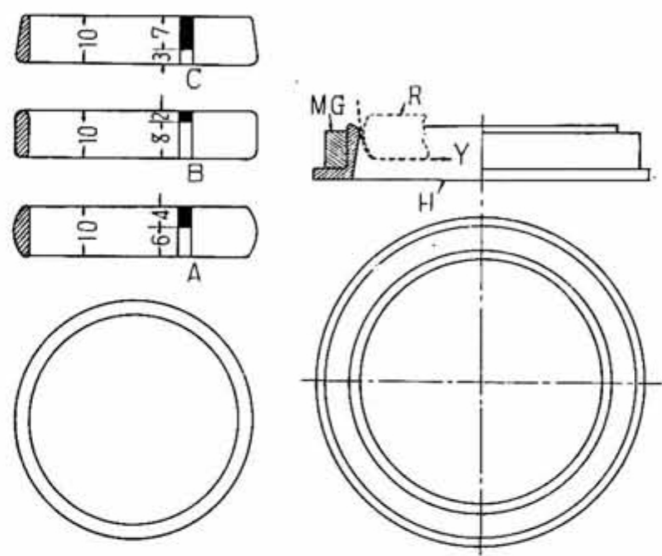

Fig. 1

Fig. 2

To see the state of contact of the yarn and the inner ring, we coated part of the outside of the inner ring with black ink. The state of the black ink being rubbed off by the yarn was observed after a predetermined time. The results are summarized in Table 1. The contact of the yarn with the ring was the slightest if the inner ring had a triangular-shaped section.

To see what variations in the spinning state would be caused by the shape of the section of the inner rings, we measured the spinning tension for each ring but found hardly any difference, exept that the inner ring having a triangular-shaped section more or less lacked in stability. It is not certain, though, that the instability was only because of the shape of the section.

To see whether yarn would differ in the amount of fuzz according to the type of the ring used, we made comparative spinning tests under the same conditions. The yarn spun with the inner ring having a rectangular-shaped section had the most fuzz. 
Table 1

\begin{tabular}{|c|c|c|c|c|}
\hline \multicolumn{3}{|c|}{ Good holder } & \multicolumn{2}{|c|}{ Other holder } \\
\hline Shape of section & D type & D type & $\triangle$ type & $\square$ type \\
\hline $\begin{array}{l}\text { Weight of inner } \\
\text { ring }\end{array}$ & $15 \mathrm{~g}$ & $21 \mathrm{~g}$ & $19 \mathrm{~g}$ & $18 \mathrm{~g}$ \\
\hline $\begin{array}{l}\text { Horizontal attrac- } \\
\text { tion force of inner } \\
\text { ring }\end{array}$ & $14 \mathrm{~g}$ & $21 \mathrm{~g}$ & $15 \mathrm{~g} \quad \begin{array}{l}\mathrm{Ir} \\
\mathrm{b} \\
\mathrm{ec} \\
\mathrm{or}\end{array}$ & $\begin{array}{l}\text { Immeasurable } \\
\text { because the } \\
\text { edge abutted } \\
\text { on the holder }\end{array}$ \\
\hline $\begin{array}{l}\text { Pulling force of } \\
\text { inner ring } \\
3 \mathrm{~mm} \text { uplift } \\
4 \mathrm{~mm} \text { uplift }\end{array}$ & $\begin{array}{l}36 \mathrm{~g} \\
46 \mathrm{~g}\end{array}$ & $\begin{array}{l}30 \mathrm{~g} \\
40 \mathrm{~g}\end{array}$ & $\begin{array}{l}36 \mathrm{~g} \\
46 \mathrm{~g}\end{array}$ & \\
\hline Gap of inner ring & adequate & adequate & adequate & e adequate \\
\hline $\begin{array}{l}\text { Reverse rotations } \\
\text { of inner ring }\end{array}$ & adequate & adequate & adequate & e adequate \\
\hline $\begin{array}{l}\text { Test spped of } \\
\text { spindle }\end{array}$ & 10,500 & 8,000 & 8,000 & 8,000 \\
\hline $\begin{array}{l}\text { Spinning tension } \\
\text { at above speed }\end{array}$ & $50 \sim 70 \mathrm{~g}$ & - & - & - \\
\hline $\begin{array}{l}\text { Float-off distance } \\
\text { of inner ring }\end{array}$ & $5 \mathrm{~mm}$ & $6 \mathrm{~mm}$ & $5 \mathrm{~mm}$ & $4 \mathrm{~mm}$ \\
\hline $\begin{array}{l}\text { Contact point } \\
\text { of yarn }\end{array}$ & & $\underset{A}{\text { Fig. } 1}$ & Fig. 1 & $\underset{\mathrm{B}}{\text { Fig. } 1}$ \\
\hline
\end{tabular}

Note: Spinning factor: same as usual ratings. Test holder: TMR 14, good quality.

Since the generation of static electricity can be considered a cause for the fuzziness of the yarn in this case, we made a comparison by spinning, under the same conditions, a pre-dried yarn and a humid yarn and found no difference between them (see Fig. 3).

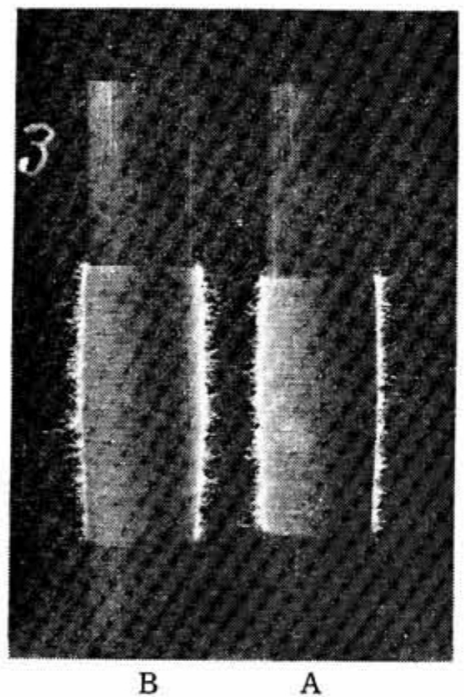

A: Dried yarn

B : Humid yorn

Fig. 3

From the results of our research on the sections of the common shapes referred to, we conclude that the best shape is the letter D with its lower edge made as round as possible. Fig. 4 is a comparison of the yarns in fuzziness.

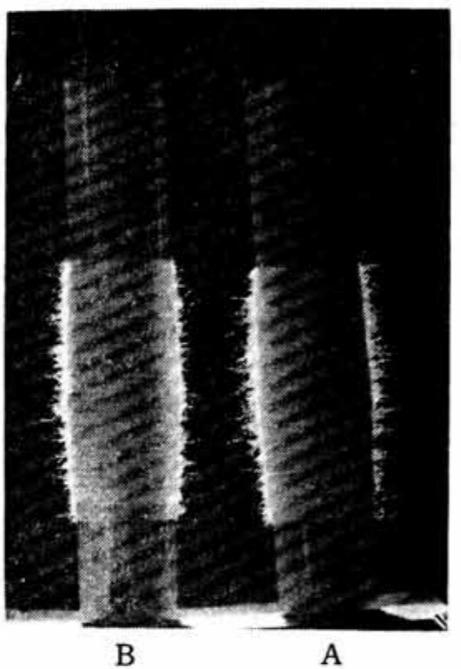

A: Fuzz of yarn spun with inner ring having a rectangular-shaped section

B: Fuzz yarn spun with inner ring shaped in the letter D

Fig. 4

As to the generation of static electricity, it may be assumed that more of it is generated in the magnetic ring than in the traveller ring. The machine used in our experiment was a conventional one with only the ring replaced.

When the new ring was put on a spinning machine in the mill, a new aluminium rail was provided to reduce the weight of the rail. The rail was so arranged that the combined weight of the rail and the magnetic ring did not exceed the weight of the ring and the conventional iron rail. Aluminium, besides being light in weight, is a non-magnetic body and does not reduce the magnetism of the magnet ring.

Valuable information as to everyday mill operations was obtained in the mill where the aluminium rail was used. For instance, we found that the aluminium rail reduced the fuzz of the yarn noticeably, as shown by the photos in Fig. 5 .

The reason why there is more fuzz in yarn in iron rail is used is not yet clear. Does the aluminium ring rail more easily discharge static electricity produced by the friction between the ring and the yarn to the ground. Or does static electrocity influence magnetism when it is discharged into the air and ionizes the nearby air? These questions remain to be answered. We expect the time will come when we can answer them. 
July $1963 \quad 146$

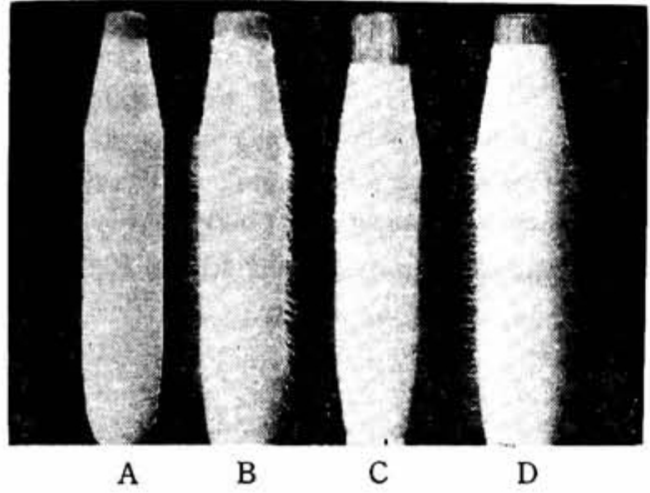

A: Yarn spun with ordinary traveller ring

B, D: Yarn spun with magnetic ring fitted on iron rail

C: Yarn spun with magnetic ring fitted on alminium rail

Fig. 5

\section{Oiling of Holder}

All our previous experiments had been made under the same spinning conditions so that the cause for variations could be easily located. The holder had never been oiled. In practice, however, so long as the inner ring contacts the inner wall of the holder while rotating, there is mutual friction between the metals. This causes wear. A conceivable remedy is to oil the holder just the same as the traveller is oiled.

To see what influence oiling would have, we made and tested a holder which could be oiled. Fig. 6 is an illustration of the holder with an oil groove provided in the perimeter of holder $\mathrm{H}$, a weak yarn wound in the groove so that it can be oiled, and hole $b$ made in the wall of the holder through which the oil oozes. An experiment also was made to see the influence of oiling on spinning tension, with the results given in Table 2 .

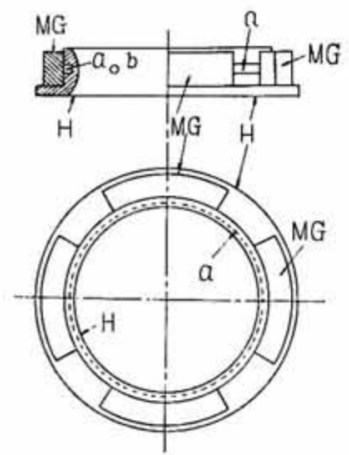

Fig. 6
Table 2

Test speed

Spinning tension

Reverse rotations of inner ring

Fozz of yarn

$\begin{array}{ll}\text { When oiled } & \text { When not oiled } \\ 7,000 \text { r.p.m. } & 7,000 \text { r.p.m. } \\ 40 \sim 45 \mathrm{~g} & 35 \sim 40 \mathrm{~g} \\ 60 \text { r.p.m. } & 69 \text { r.p.m. } \\ \text { Unchanged } & \text { Unchanged }\end{array}$

Note: (1) Spinning conditions were the same as the conventional ratings.

(2) Both were operated under the same conditions at the same time.

(3) The holder shown in Fig. 6 used in this expcriment.

The foregoing table shows that oiling the holder reduced the spinning tension by about $10 \%$ and besides, kept the rotations stable. Further, the fact that the reverse rotations of the inner ring were increased by about $15 \%$ by oiling the holder indicates an improvement in the spinning conditions. However, there was no difference in the amount of fuzz in yarn between oiling and non-oiling the holder.

The oil applied to the holder spread from the inner wall of the holder to the inner ring and reduced the friction of the yarn and the inner ring, too. Table 3 shows the difference in spinning conditions between oiling and non-oiling another holder. In this case too, spinning tension was reduced by about $20 \%$.

Table 3

\begin{tabular}{|c|c|c|}
\hline & When oiled & When not oiled \\
\hline Test speed & 9,000 r.p.m. & 9,000 r.p.m. \\
\hline Spinning tension & $45 \sim 50 \mathrm{~g}$ & $35 \sim 40 \mathrm{~g}$ \\
\hline $\begin{array}{l}\text { Reverse rotations } \\
\text { of inner ring }\end{array}$ & -94 r.p.m. & -107 r.p.m. \\
\hline Fozz of yarn & Unchanged & Unchanged \\
\hline
\end{tabular}

Note: (1) Spinning conditions were the same as the conventional ratings.

(2) Both were operated under a same condition at the same time.

(3) The holder used was No. TMR 14, good quality, operable at more than 10,000 r.p.m.

Spinning tension is produced by the centrifugal force of the revolving yarn and air resistance and is considered to be proportional to the number of re. volutions of the spindle. A $10 \%$ decrease in spinning tension, then, should increase the number of 
revolutions by about $5 \%$ over the number of revolutions if the holder is not oiled.

It is an apparent paradox that oiling of a holder produces a lubricating effect but, as reported in a previous instalment, hinders the rotating movement of the inner ring because the plating on the holder causes slippage. The apparent effect of oiling and plating is the same, exept that, if a holder is oiled, the oil spreads to the inner ring also and the effect of oiling acts on the yarn, too.

Just as an oil top is suitable for cap spinning, so a slight extra supply of oil to a dry top is helpful in reducing fuzz and stabilizing the spinning conditions.

\section{Conclusions}

We have published, over a period of about a year, data on part of a basic research on the mag. netic ring.

The magnetic ring being an entirely new invention, we lacked reference material and appraised its characteristics mainly by experiments, advancing theories as best we could with our limited knowledge. However, manufacturing data and information as to the serviceability of the ring have been obtained sufficiently, we believe, to be immediately useful.

The magnetic ring has now been put in massproduction, is being experimentally used on spinning machines in mills and will be put on the market in the near future.

Research on the traveller ring has progressed rapidly, and the worsted ring frame has been improved steadily untill it can now at a spindle speed of 14,000 r.p.m. However, this spindle speed is not practical in the spinning system of marking balloons by wielding the yarn. Even if the spin. ning machine can revolve 14,000 r.p.m., the practical maximum speed is considered to be 12,000 r.p.m., if a $50 \mathrm{~mm}$-ring is used.

The merit of the magnetic ring (it can revolve more than 10,000 r.p.m.) may have been lessened more or less by the improvement of the traveller ring, but its other advantages still shine. It is suitable to a wide range of deniers, saves the trouble of replacing the traveller, and saves also the trouble of always preparing travellers of various deniers in the mill.

The magnetic ring is considered capable of revolving to a maximum of 14,000 r.p.m., but it may be difficult to use the present traveller ring frame with the magnetic ring running at this speed. The machine will have to be re-designed as a magnetic ring spinning machine with a new method of operation. Mill experiments are being made by using the traveller ring, presently in common use, with only its rail replaced by a rail suited to the magnetic ring, but the practical maximum speed in this case is considered to be about 12,000 r.p.m.

This concludes our report on the magnetic ring in the initial stage of experimenting. A report on mill experiments will follow at a future date.

\section{Literature cited}

[1] Textile Praxis, Eng. Ed. II. (1960) 